\title{
EXTRACTO DE REVISTAS
}

\section{Di Paolz G., Vázquez Ferro E. y Mieres A.}

Pólipos placentarios. Obst. Gin. Lat.-Amer., 1956. Vol. XIV. Nov., Dic., Nọ 11/21, página 99 .

Los autores presentan tres casos de pólipos placentarios. Se detalla una breve reseña de las opiniones de diversos autores con respecto a esta afección y las distintas denominaciones de que ha sido objeto.

A continuación se transcriben las historias clínicas de los casos observados.

Después de efectuar una breve descripción anatomopatológica de estos pólipos, los autores creen correcta la denominación de "pólipos placentarios", sin haber observado en los casos presentados signos de proliferación.

Se describe la sintomatología y los elementos de diagnóstico y luego los relaciona con las observaciones propias.

El tratamiento, que aunque debe ser siempre quirúrgico, los autores lo contemplan desde el punto de vista de la cirugía radical y conservadora, fijando su propia posición.

\section{Autorresumen.}

Ficha número 2.377 de “Obstetricia y Ginecología-LatinoAmericanas".

Gori R. M. y Oliveira C. - Acción de las hormonas sexuales sobre la cristalización del moco cervical. Obst. Gin. Lat. Amer., 1957 Vol. XV, Nọ 3|4, pág. 108.

El tapón mucoso del cuello uterino extendido convenientemente en un portaobjetos y dejado secar, muestra, a la observación microscópica, formaciones cristalíferas características. Se deben al cloruro de sodio presente en el moco cervical y se producen sólo por la acción de los estrógenos circulantes. Los auto- 
res estudian la acción de los estrógenos, progesterona y testosterona, sobre la cristalización del moco cervical en 179 casos. Tanto en la mujer menopáusica como en las que padecen de insuficiencia ovárica, dosis pequeñas de estrógeno, de 0.5 a 1 miligramo de benzoato de estradiol, son suficientes para provocar la cristalización; pero en la mujer embarazada no se logra obtener tal fenómeno aún administrando dosis muy elevada de estrógeno. La fácil respuesta que se obtiene en la mujer amenorréica con moco negativo, podría servir de "test" de embarazo.

La progesterona no manifiesta su acción de manera ostensible, como lo hace en otros sectores del organismo; las modificaciones más apreciables consisten en una disminución de la cantidad y espesamiento del moco, debidas probablemente a una mayor cantidad de mucina secretada. Es posible también, que se deban a este hecho las peculiaridades de la cristalización de la segunda mitad del ciclo.

La testosterona influencia poco al proceso de cristalización, pero administrada en altas dosis también ocasiona la disminución de la cantidad y de la fluidez del moco cervical.

\section{Autorresumen.}

Ficha número 2.378 de "Obstetricia y Ginecología LatinoAmericanas".

Lernoud M. - Ensayo de analgesia obstétrica potencializaca por asociación de fenergán, largactil y demerol.

Estudio de cincuenta casos. Obst. Gin. Lat. Amer., 1957. Vol. XV, número $3 \mid 4$, pág. 112 .

Luego de pasar revista a algunos trabajos clínicos y experimentales sobre la analgesia obstétrica potencializada, se estudian 50 partos medicados según el siguiente esquema:

1) Al comienzo del trabajo: 1 ampolla de Fenergán intramuscular.

2) Con 4 o 5 centímetros: 1 ampolla de Demerol +1 ampolla de Ampliactil + 1 ampolla de Coramina por vía intramuscular.

3) Con dilatación completa: 1 ampolla intramuscular de Flaxedil.

Aparte del fracaso del Flaxedil, se considera conveniente continuar los ensayos con este tipo de medicación, por ser de 
fácil administración, anodina para la madre y el feto, y por el alto porcentaje de analgesias buenas y muy buenas que se obtiene $(98 \%)$.

\section{Autorresumen.}

Ficha número 2.379 de "Obstetricia y Ginecología LatinoAmericanas".

Nogués A. E. - Garcinoma mamario inaparente (oculto). obst. Gin. Lat.-Amer., 1957, Vol. XV, número 3|4, pág. 117.

Después de un estudio bibliográfico, se analizan 6 observaciones propias destacando sus características más sobresalientes. se resume en las cinco conclusiones siguientes lo esencial de este trabajo, a saber:

El cuadro designado como carcinoma mamario inaparente $u$ oculto, se caracteriza clínicamente por la existencia de una adenopatía axilar tumoral, sin que se pueda reconocer el tumor primitivo mamario. Su frecuencia alcanzó en nuestra práctica al $0,94 \%$.

El diagnóstico exige una exploración clínica mamaria minuciosa, exacta valorización de los antecedentes (mastopatía crónica quística), investigación de la vía canalicular (examen citológico del derrame), etc., y la resección ganglionar con examen anatomopatológico del ganglio.

Confirmado el carácter carcinomatoso secundario de la adenopatía, del tipo mamario, se efectuará si el caso clínico lo pernite, la operación radical seguida. 